\title{
Morgagni hernisine bağlı mekanik barsak obstrüksiyonu
}

\author{
Mechanical intestinal obstruction due to Morgagni hernia \\ Üstün $\mathrm{M}$ Yoldaş $\mathrm{T}$ Akgün $\mathrm{E}$ \\ Ege Üniversitesi Tıp Fakültesi, Genel Cerrahi Anabilim Dalı, İzmir, Türkiye
}

\section{Özet}

Morgagni hernisi erişkinlerde nadir görülen ve karın içi organların retrosternal olarak toraksa yer değiştirdiği bir konjenital diyafram hernisidir. Burada mekanik barsak obstrüksiyonu tablosu ile acil servise başvuran Morgagni hernili bir olgu bildirilmiştir. Yapılan tetkikler sonrasında Morgagni hernisine bağlı mekanik barsak obstrüksiyonu saptandı. Hastaya acil laparotomi sonrasında redüksiyon uygulandı ve defekt primer onarıldı. Mekanik barsak obstrüksiyonu ayrıcı tanısında, ender bir sebep de olsa, Morgagni hernisi akılda tutulmalıdır.

Anahtar Sözcükler: Diyafram hernisi, obstrüksiyon, laparotomi.

\section{Summary}

Morgagni hernia, is a congenital diaphragmatic type hernia which is rare in adults and contains the displacement of the abdominal organs to the thorax the retrosternal space. We report on a case which was admitted to the emergency department with a mechanical intestinal obstruction. After medical examinations, a mechanical intestinal obstruction due to Morgagni hernia was diagnosed. The patient underwent emergency laparotomy and a reduction and primary repair of the defect was performed. In the differential diagnosis of mechanical intestinal obstruction, a Morgagni hernia should be kept in mind although it is a rare cause.

Key Words: Diaphragmatic hernia, obstruction, laparotomy.

\section{Giriş}

Embriyolojik dönemin 3. ve 12. haftaları arasında barsakların karna göçü ve diyafram oluşumu gerçekleşir. Bu dönemde gerçekleşecek bir anomali ya da gecikme sonucu konjenital diyafram hernileri meydana gelir (1). Morgagni hernisi çok nadir görülen bir konjenital diyafram hernisi türüdür. Tüm konjenital diyafram hernileri 5000 doğumda 1 görülürken bunlardan \%2 sini Morgagni hernisi oluşturur (2). Morgagni hernisi, diyaframda anteromedial lokalizasyonlu bir defekt sonucu meydana gelir $(1,3)$. Defekt, diyafram kruslarının kondral ve sternal komponentlerinin gelişmemesi sonucu oluşmaktadır ve genelikle sağ taraf yerleşimlidir. Nadir olarak sol tarafta ya da bilateral olabilmektedir (4). Hemen hepsi fıtık kesesi içerir. Kese içerisinde en sık omentum, ardından kolon, bazen de ince barsaklar ve diğer karın içi organlar bulunur (4). Morgagni hernisi klinik olarak genellikle asemptomatiktir ve tesadüfen radyolojik tetkikler esnasında saptanır.

\footnotetext{
Yazışma Adresi: Mehmet ÜSTÜN

Ege Üniversitesi Tıp Fakültesi, Genel Cerrahi Anabilim Dalı, İzmir, Türkiye
}

Fıtık kesesinin büyüklüğüne bağlı olarak göğüs ağrısı ya da nefes darlığına neden olabilir. Daha nadir olarak ta fıtık kesesi içindeki barsak ansının sıkışması nedeniyle mekanik barsak obstrüksiyonu tablosu ile karşımıza çıkabilir. Bu yazıda, mekanik barsak obstrüksiyonu tablosu ile başvurup opere edilen Morgagni hernisi olgusu sunulmuştur.

\section{Olgu Sunumu}

80 yaşında erkek hasta 3 gündür devam eden karın ağrısı, gaz-gaita çıkaramama yakınması ile Ege Üniversitesi Tıp Fakültesi Acil Servise başvurdu. Başvuru anında vital fonksiyonları olağandı. Hastanın yandaş ek hastalığı ve geçirilmiş cerrahisi bulunmamaktaydı. Hastanın yapılan fizik muayenesinde; karın minimal distandü görünümdeydi, barsak sesleri metalik vasıftaydı. Epigastrik bölgede hassasiyet, defans, rebound mevcuttu. Kardiyak muayenesi olağandı. Solunum sistemi muayenesinde, oskültasyonda, sağ hemitoraksta solunum sesleri kısmen azalmıştı. Akciğer grafisinde sağ alt zonda dansite artışı mevcuttu (Şekil-1). Ayakta direkt karın grafisinde ince barsak düzeyinde hava-sıvı seviyeleri izlendi (Şekil-2). 


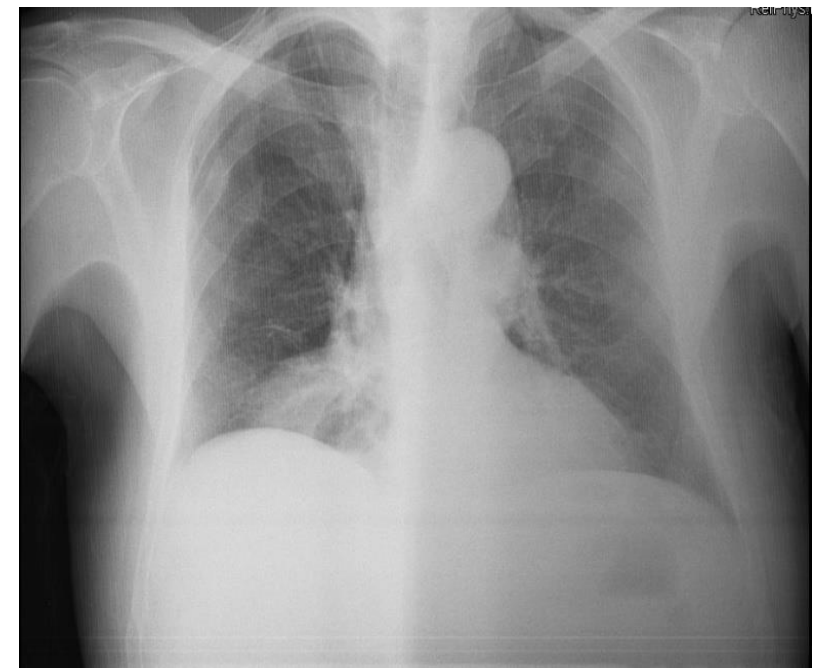

Şekil-1. Sağ alt zonda opasite.

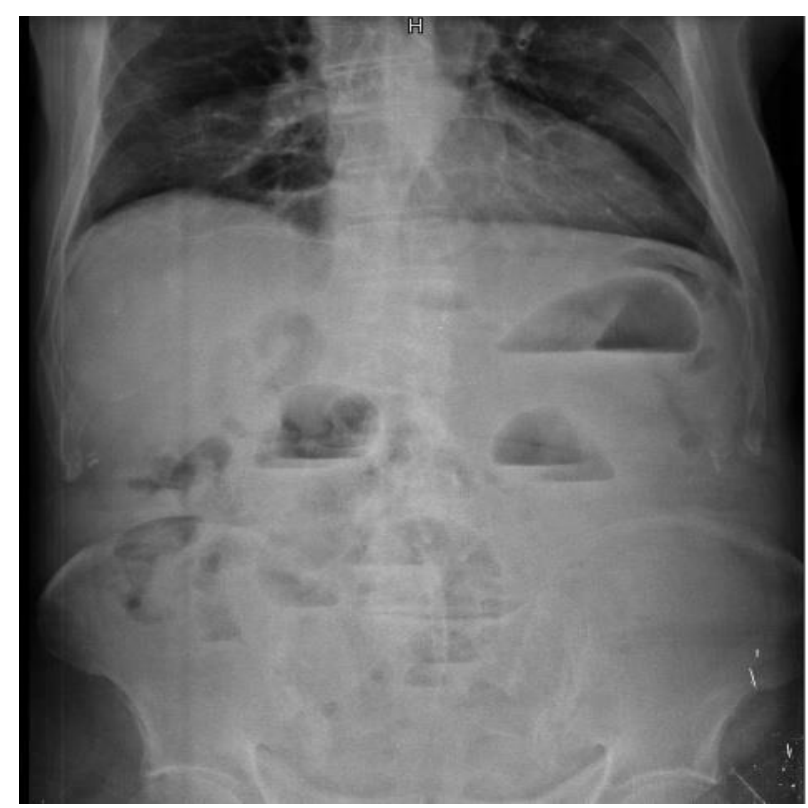

Şekil-2. İnce barsak düzeyinde hava sıvı seviyeleri.

Hastanın laboratuvar değerleri, CRP:3,4 mg/dL ve lökosit: $13.600 / \mathrm{mm}^{3}$ dışında normal sınırlardaydı. Mekanik barsak obstrüksiyonunun etiyolojisini aydınlatmak için bilgisayarlı tomografi (BT) uygulandı. BT'de Morgagni hernisi ile uyumlu diyaframda defekt ve defekt içerisinde sıkışmış ince barsak ansı görüldü (Şekil-3). Hasta acil şartlarda operasyona alındı. Median superior insizyonla karına girildi. Eksplorasyonda diyafram anteriorunda, sağ tarafta retrosternal alanda yaklaşık 4 cm'lik defekt mevcuttu (Şekil-4) ve $10 \mathrm{~cm}$ 'lik jejunum ansının inkarsere olduğu görüldü. İnce barsak redükte edildi ve sıkışan ince barsak ansında herhangi bir iskemi ya da nekroz görülmediğinden rezeksiyon uygulanmadı. Diyaframdaki defekt primer onarıldı. Hastada operasyon sonrası herhangi bir komplikasyon gelişmedi. Hasta postoperatif 5 . günde şifa ile taburcu edildi.

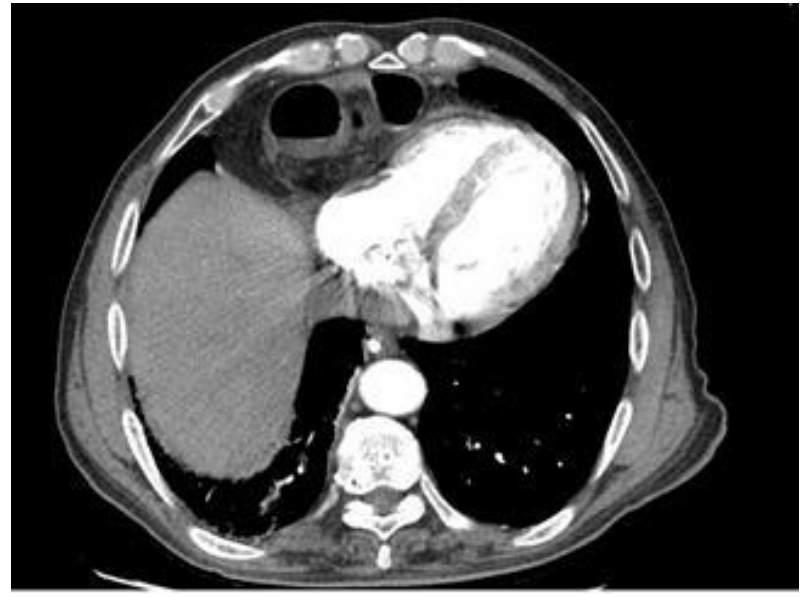

Şekil-3. Toraksa herniye olmuş ince barsak.

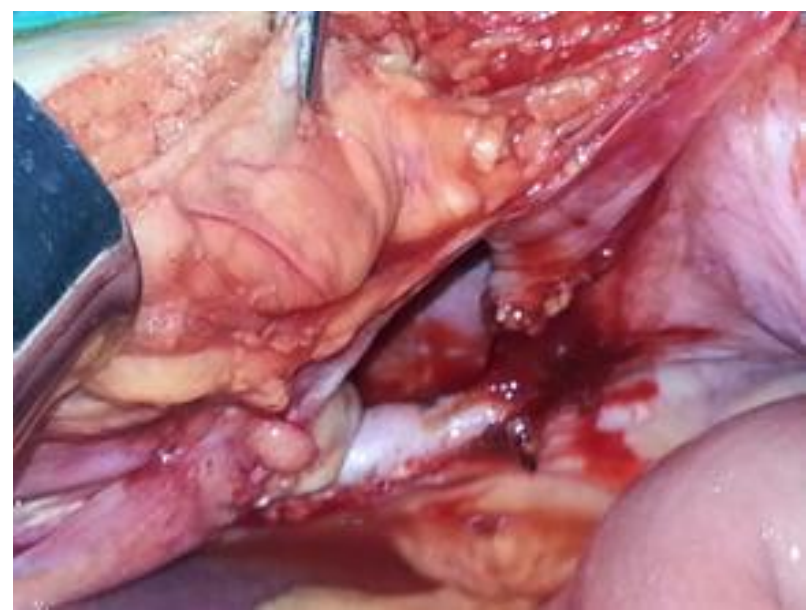

Şekil-4. Karından defektin görünümü.

\section{Tartışma}

Erişkinde Morgagni hernisi nadir görülen ve genellikle asemptomatik seyreden konjenital bir diyafram hernisidir (5-6). Semptomatik olgularda, semptomlar, defektin büyüklüğüne, defekt içerisinde yer alan organa ve bu organın sıkışmasına bağlı olarak değişir $(2,3)$. Semptomlar solunum sıkıntısı ile ilgili olabileceği gibi, karın içi organlar ile ilişkili de olabilir. Bizim sunduğumuz olgu, mekanik barsak obstrüksiyonu tablosu ile başvurdu. Solunum sistemi ile ilgili yakınması mevcut değildi.

Tanıda görüntüleme yöntemlerinden direkt grafiler yardımcıdır. Direkt grafilerde toraksta opasite ve karında hava sıvı seviyelerinin olması önemli bulgulardır. Lümenli bir organ herniasyonu yoksa hava sıvı seviyesi görülmez. Yine fıtıklaşma aralıklı oluyor ise akciğer grafisi olağan olabilir. Şüphe varsa intravenöz ve oral opaklı tomografiler tanıda oldukça faydalıdır $(3,6)$.

Semptomatik Morgagni hernisi tanısı alan tüm erişkinler cerrahi olarak tedavi edilmelidir. Çocuklar da ise tanı anında herhangi bir semptom görülmese dahi cerrahi 
önerilmektedir. Asemptomatik olan ve tesadüfen tanı alan erişkin hastaların cerrahi tedavisi tartışmalıdır (2). Bazı yazarlar inkarserasyon ve strangülasyon riskinden dolayı asemptomatik olgularda da cerrahi önermektedirler (2). Herniye olan organın kolon olduğu durumlarda inkarserasyon ve strangülasyon riski daha yüksek olduğundan cerrahi tedavi daha sık önerilmektedir (8). Bizim olgumuz obstrüksiyon tablosu ile başvurduğundan acil şartlarda opere edilmiştir.

Morgagni hernisi, diğer bir konjenital diyafragma hernisi olan Bochdalek hernisinin aksine, genellikle bir fitık kesesine sahiptir (1). Operasyon anında fıtık kesesinin çıkarılıp çıkarılmaması tartışmalı bir konudur. Bir kısım yazar gelişebilecek masif pnömomediastinum riskinden dolayı fıtık kesesinin çıkarılmaması gerektiğini savunurken (9), bir kısım yazar toraksta yer kaplayıcı lezyon kalmaması açısından fıtık kesesinin eksize edilmesi gerektiğini savunmuşlardır (10). Bizim olgumuzda fıtık kesesi küçük olduğundan ve hastanın solunum fonksiyonları etkilenmediğinden eksize edilmemiştir.

Sonuç olarak, mekanik barsak obstrüksiyonu tablosu ile başvuran ve solunum sistemi ile ilgili yakınması olan hastalarda Morgagni hernisi ayırıcı tanıda akılda tutulmalıdır. Karın içi organlar ile ilgili semptomu olan hastalarda cerrahi gerekmektedir, strangülasyon riskinden dolayı asemptomatik erişkin olgularda da tanı anında cerrahi tedavi uygulanmasını önermekteyiz.

\section{Kaynaklar}

1. Shields TW. Embryology and anatomy of the diaphragm. In: Shields TW, (ed). General Thoracic Surgery. 4th ed. Malvern, PA: Williams and Wilkins; 1994: 41-56.

2. Barut I, Tahran OR, Cerci C, Akdeniz Y, Bulbul M. Intestinal obstruction caused by a strangulated Morgagni hernia in an adult patient. J Thorac Imaging 2005;20(3):220-2.

3. Bragg WD, Bumpers H, Flynn W, Hsu HK, Hoover EL. Morgagni hernias: A common cause of chest masses in adults. Am Fam Physician 1996;54(6):2021-4.

4. Okutan H, Uçan ES, Silistireli E, Oto Ö. Erişkin Morgagni hernisinde transtorasik yaklaşım. Toraks Dergisi 2000;1(1):79-81.

5. Swain JM, Klaus A, Achen SR, Hinder RA. Congenital diaphragmatic hernia in adults. Semin Laparosc Surg 2001;8(4):246-55.

6. Kilic D, Nadir A, Doner E, et al. Transthoracic approach in surgical management of Morgagni hernia. Eur J Cardiothorac Surg $2001 ; 20(5): 1016-9$

7. Fornero G,Roseto L, Coluccio G. Intestinal occlusion caused by Morgagni-Larrey diaphragmatic hernia. Minerva Chir 1998;53(1-2):57-60.

8. Loong TP, Kocher HM. Clinical presentation and operative repair of hernia of Morgagni. Postgrad Med J 2005;81 (951):41-4.

9. Kuster GG, Kline LE, Garzo G. Diap-hragmatic hernia through the foramen of Morgagni: Laparoscopic repair case report. J Laparoend Surg 1992;2(2):93-100.

10. Rau HG, Schardey HM, Lange V. Laparoscopic repair of a Morgagni hernia. Surg Endosc 1994;8(12):1439-42. 